\title{
Bimodal immunoglobulin A gammopathy in a cat with feline myeloma-related disorders
}

\author{
Masaya IGASE ${ }^{1)}$, Takako SHIMOKAWA MIYAMA ${ }^{2) *}$, Satoshi KAMBAYASHI ${ }^{3)}$, Yumiko SHIMOYAMA ${ }^{4}$, \\ Hiroko HIRAOKA ${ }^{4)}$, Yumi HIRATA ${ }^{5)}$, Miki IWATA ${ }^{5)}$, Kenji BABA ${ }^{2)}$, Takuya MIZUNO ${ }^{1)}$ and Masaru OKUDA ${ }^{2)}$ \\ 1)Laboratory of Molecular Diagnostics and Therapeutics, Joint Faculty of Veterinary Medicine, Yamaguchi University, Yamaguchi \\ 753-8515, Japan \\ ${ }^{2)}$ Laboratory of Veterinary Internal Medicine, Joint Faculty of Veterinary Medicine, Yamaguchi University, Yamaguchi 753-8515, Japan \\ ${ }^{3)}$ Laboratory of Veterinary Internal Medicine, The United Graduate School of Veterinary Science, Yamaguchi University, Yamaguchi \\ 753-8515, Japan \\ 4)IDEXX Laboratories, Higashi-Koganei, Tokyo 184-8515, Japan \\ ${ }^{5)}$ Hirata Animal Hospital, Yamaguchi 753-0843, Japan
}

(Received 19 March 2015/Accepted 17 November 2015/Published online in J-STAGE 4 December 2015)

\begin{abstract}
A 10-year-old female spayed mixed breed cat with a subcutaneous mass on the right hind limb was revealed with bimodal monoclonal gammopathy composed of IgA by immunoelectrophoresis and immunofixation. Approximately 1 month after referral, the cat died due to renal failure. Postmortem immunohistopathologic evaluation of the subcutaneous mass revealed neoplastic cell proliferation of plasma cells and giant myeloma cells. Neoplastic cells were also present in the liver and spleen. These results led to the diagnosis of a rare case of feline myeloma-related disorders with extramedullary plasmacytoma infiltrating in multiple locations. This report emphasizes the necessity to accumulate cases with similar clinicopathologic findings in the future.
\end{abstract}

KEY WORDS: feline, hyperproteinemia, immunofixation, oncology, plasma cell disorder

doi: 10.1292/jvms.15-0156; J. Vet. Med. Sci. 78(4): 691-695, 2016

Myeloma-related disorders (MRDs) are neoplastic diseases of plasma cells or immunoglobulin-secreting B-lymphocyte precursors. Feline MRDs are rare, accounting for $0.0012-0.0025 \%$ of all feline cancers $[2,4]$. Human MRDs and canine MRDs account for $1-2 \%$ of all human neoplasias and up to $1 \%$ of all canine tumors $[16,29]$. Holzworth and Meier reported the first case of feline MRDs in 1957 [9]. However, the definition of these disorders was not clarified until Mellor et al. classified the diagnostic criteria of feline MRDs in 2006 [18]. Feline MRDs are categorized into multiple myeloma, cutaneous or noncutaneous extramedullary plasmacytoma, solitary plasmacytoma of the bone, Waldenstrōm's macroglobulinemia of immunoglobulin M, immunoglobulin-secreting lymphoma and leukemia, and plasma cell leukemia. The histologic and cytologic features of these disorders have only been described by one publication and a few case reports [8, 14, 19, 24]. Therefore, more information on the clinical features of feline MRDs is required. The present report describes the clinicopathologic and immunohistopathologic features of a cat with the bimodal IgA gammopathy in feline MRDs.

A 10-year-old female spayed mixed-breed cat was referred to Yamaguchi University Animal Medical Center for

*Correspondence to: Shimokawa Miyama, T., Laboratory of Veterinary Internal Medicine, Joint Faculty of Veterinary Medicine, Yamaguchi University, Yoshida 1677-1, Yamaguchi 753-8515, Japan. e-mail: tshimo@yamaguchi-u.ac.jp

C2016 The Japanese Society of Veterinary Science

This is an open-access article distributed under the terms of the Creative Commons Attribution Non-Commercial No Derivatives (by-nc-nd) License $<$ http://creativecommons.org/licenses/by-nc-nd/4.0/>. evaluation of a subcutaneous mass on the right hind limb that had been growing for 2 weeks (Fig. 1). The mass was approximately $40 \mathrm{~mm}$ in diameter and immovable. Physical examinations found no detectable abnormalities, such as enlargement of the popliteal and inguinal lymph nodes or visible mucous membrane abnormalities. Complete blood cell count analysis showed no significant abnormalities (PCV: $43 \%$; reference range $24-55 \%$, WBC: $17,240 / \mu l$; reference range 5,500-19,500/ $\mathrm{l}$, segmented neutrophils $15,520 / \mu l$; reference range 4,000-15,000/ $\mathrm{ll}$ and lymphocytes $1,720 / \mu \mathrm{l}$; reference range $1,000-3,000 / \mu l$ ). Biochemical blood testing showed no abnormalities, except for hyperproteinemia (total serum protein $10.0 \mathrm{~g} / \mathrm{d} l$; reference range $6.0-8.0 \mathrm{~g} / \mathrm{d} l$ ). Results of feline immunodeficiency virus (FIV) antibody/feline leukemia virus (FeLV) antigen tests were negative (SNAP FIV/FeLV comb; IDEXX Laboratories, Tokyo, Japan). Chest and abdominal X-rays showed no abnormalities. Bone radiography including the right hind limb did not reveal any multifocal punctate areas. Hypoechoic lesions of the spleen were detected by ultrasound examination. Fine needle aspiration biopsy was performed on the subcutaneous mass for cytological examination. Large amounts of atypical round cells were observed within a monomorphic cell population, suggesting neoplastic disease (Fig. 2). These tumor cells had immature, often eccentrically located, round to oval nuclei with a fine chromatin pattern, and had several prominent nucleoli. Bi- or multinucleated giant cells were also observed occasionally. Based on these findings, cytological differential diagnoses included extramedullary plasmacytoma, lymphoplasmacytic lymphoma and undifferentiated round cell tumor. Bone marrow aspiration was performed in the bilateral humeral head and right humeral body to rule out metastasis of the tumor, 


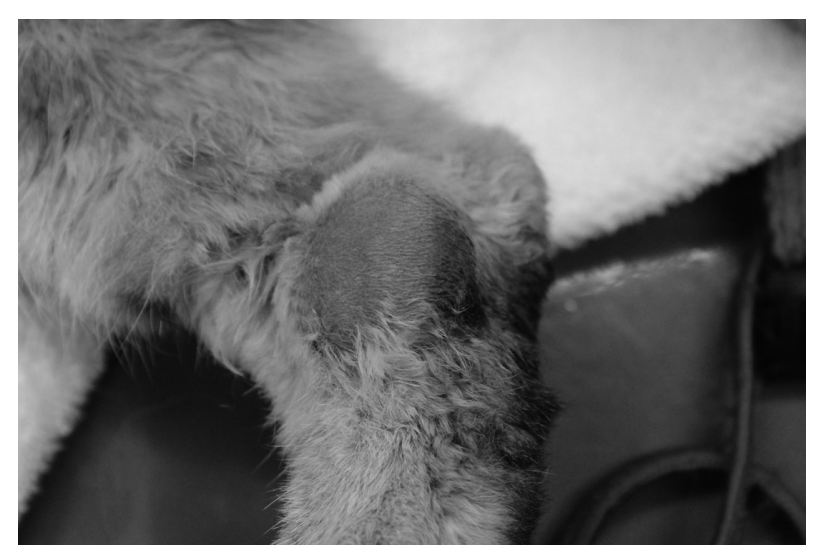

Fig. 1. A subcutaneous mass was observed on the right hind limb of a cat. The mass was approximately $40 \mathrm{~mm}$ in diameter.

and no abnormality was found. Upon urinalysis, Bence-Jones proteins could not be measured due to lack of the inspection in Japan. However, 1 peak in the gamma region was detected with urine protein electrophoresis. We could guess that either the immunoglobulin or its light chain was leaked in the urine. Serum protein electrophoresis and immunofixation analysis were performed at Veterinary Diagnostic Laboratories in Colorado State University. The albumin fraction was found to be decreased (albumin/ globulin ratio is 0.23 ; reference range $>1.00$ ), and there were 2 discrete peaks in the gamma region, compatible with a biclonal gammopathy (Fig. 3A). Immunofixation analysis showed 2 discrete bands in the IgA lane with corresponding bands in the light chain lane (Fig. 3B). A broad band in the IgG lane was interpreted as a polyclonal response. Rabbit anti-cat whole serum polyclonal antibody, goat anti-cat IgM polyclonal antibody [21], rabbit anti-cat IgG heavy and light chain polyclonal antibody [21], goat anti-cat IgA polyclonal antibody [20] and goat anti-cat light chain (including both kappa and lambda patterns) polyclonal antibody [20] were used and confirmed the specificity by Veterinary Diagnostic Laboratories in Colorado State University. All antibodies were obtained from the Bethyl Laboratories Inc. (Montgomery, AL, U.S.A.). Considering the above findings combined with the clinical signs, laboratory findings and cytological examination results, we made a provisional diagnosis of extramedullary plasmacytoma or lymphoplasmacytic lymphoma. The owner selected a single treatment of prednisolone. Approximately 1 month later, biochemical blood testing showed azotemia (blood urea nitrogen 126.4 $\mathrm{mg} / \mathrm{d} l$; reference range, $9.2-29.2 \mathrm{mg} / \mathrm{d} l$ ), high creatinine concentration (creatinine $5.2 \mathrm{mg} / \mathrm{d} l$; reference range, $0.4-1.4 \mathrm{mg}$ / $\mathrm{d} l$ ) and hyperproteinemia (total serum protein $10.5 \mathrm{~g} / \mathrm{d} l$ ). The cat was hospitalized and treated by the intravenous fluid infusion. Unfortunately, after three days treatment, the cat died due to renal failure, which was probably associated with hyperviscosity syndrome. Necropsy was performed, and tissue samples (the subcutaneous mass, liver, spleen and kidneys) were collected for histopathology. The samples were fixed in $10 \%$ neutral-buffered formalin, embedded in paraffin and

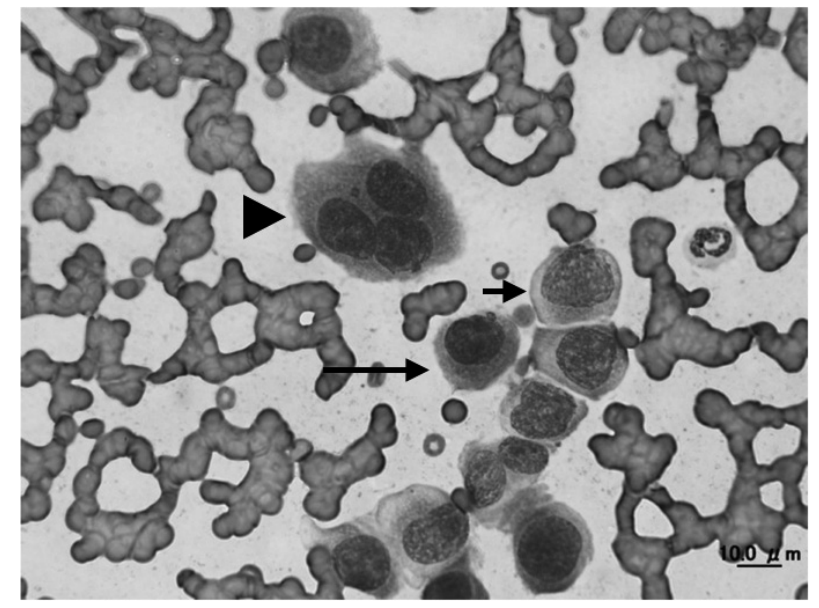

Fig. 2. Fine-needle aspirate from the cat with extramedullary plasmacytoma of a subcutaneous lesion. Immature (short arrow) and mature (long arrow) plasmacytoid cells were observed. In addition, scattered giant multinuclear cells (arrowhead) were seen. Giemsa staining. $\times 1,000$ objective.

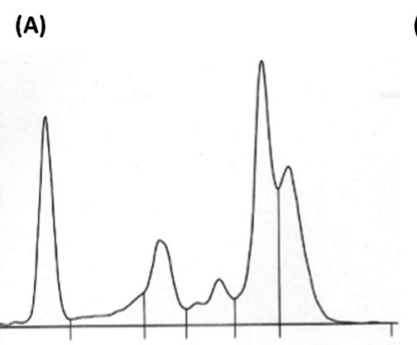

Alb. $\begin{array}{llll}\alpha_{1} & \alpha_{2} & \beta & \gamma\end{array}$
(B)

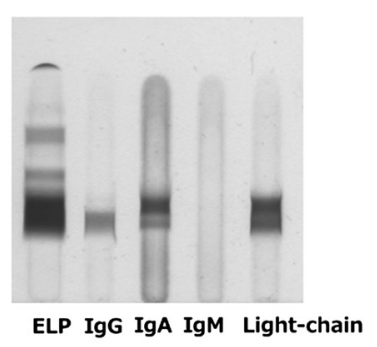

Fig. 3. Serum protein electrophoresis illustrating bimodal monoclonal gammopathy in a cat (A). Immunofixation analysis in the cat (B). Two discrete bands in the IgA lane with corresponding bands in the light chain lane were observed. The used antibodies were described in the manuscript. The gel has one lane for light chains of both kappa and lambda patterns.

stained with hematoxylin and eosin. Histologically, significant infiltration of neoplastic round cells with plasmacytic features was seen in the liver, spleen and subcutaneous mass (Fig. 4A4D). These cells had similar morphologic features to those observed by cytology; however, the degree of differentiation ranged from those resembling mature plasma cells to very large round cells (plasmablasts). In the subcutaneous lesion, the tumor cells infiltrated into the deep dermis extending to the subcutaneous layer and formed a sheet-like structure (Fig. 4A). These cells were composed mainly of intermediately differentiated proplasmacytes with a small number of mixed mature plasma cells and poorly differentiated plasmablasts (Fig. 4B). The proplasmacytes were larger than the mature plasma cells, with greater anisocytosis and asynchronous nuclear and cytoplasmic maturation. They had eccentrically located large nuclei containing indistinct or small nucleoli. In contrast to the subcutaneous mass, the neoplastic cells seen 

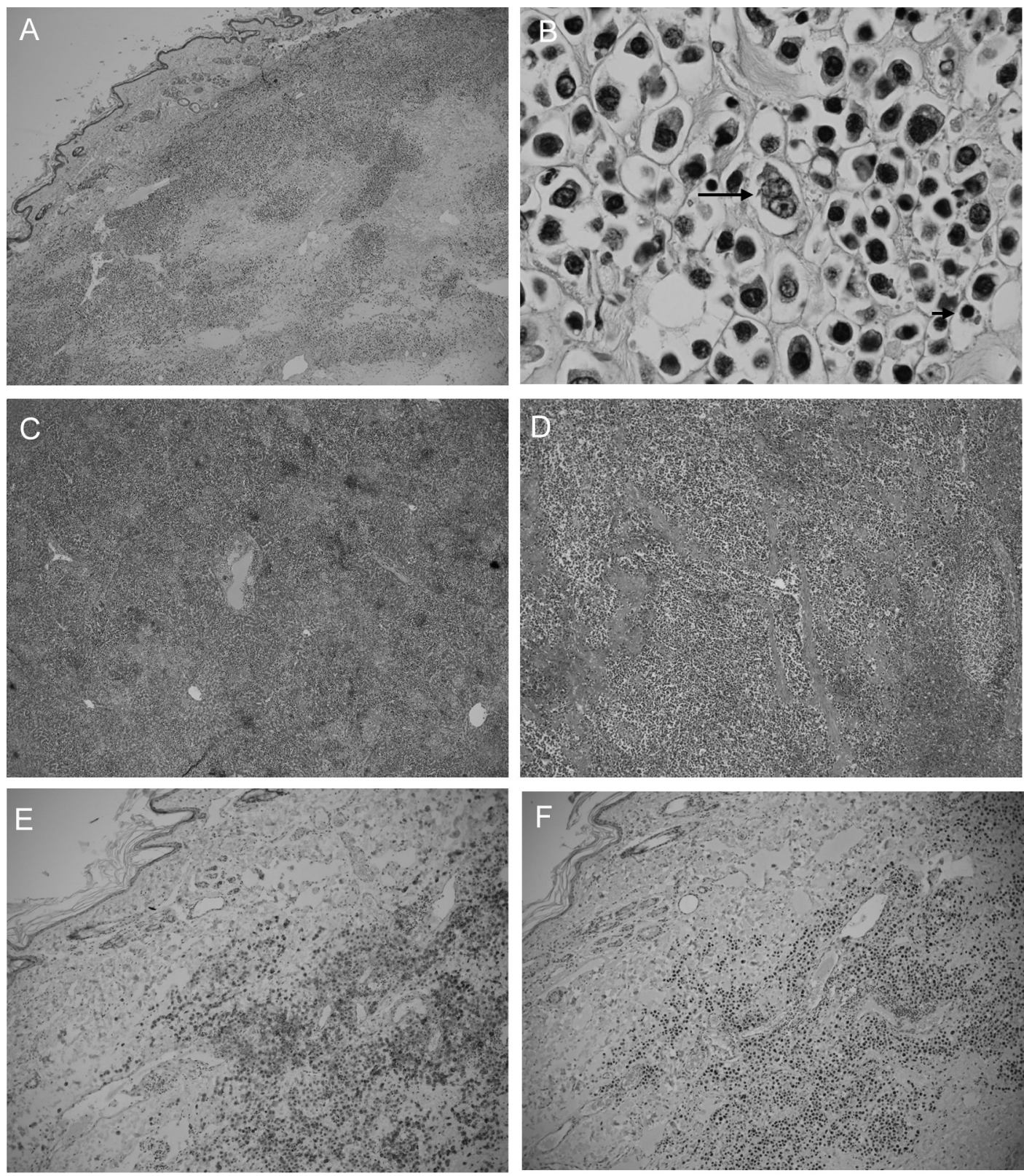

Fig. 4. Post mortem histopathological examination of the subcutaneous mass (A, B), liver (C) and spleen (D). Tumor cells infiltrated all three tissues. Cells (B) were composed mainly of proplasmacytes with a small number of mature plasma cells (short arrow) and plasmablasts (long arrow). Hematoxylin and eosin staining. (A, C and D) $\times 10$ objective and $(\mathrm{B}) \times 100$ objective. The subcutaneous mass is positive for CD79a (E) and MUM1 (F). Hematoxylin counterstain. (E, F) $\times 10$ objective.

within the liver and spleen showed more pleomorphism with a predominance of poorly differentiated plasmablasts (data not shown). The plasmablasts were much larger than the mature plasma cells, with greater anisocytosis. They had a narrow rim of cytoplasm and a less distinct or unapparent perinuclear clear zone. They also had a high nuclear:cytoplasmic ratio and a large, immature, round to ovoid nucleus with prominent nucleoli. These cells were clustered together and formed multinodular lesions within the organs. Giant myeloma cells that contained a large, bizarre, segmented nucleus or multiple nuclei were seen occasionally in the liver and spleen. Both kidneys were found to contain moderate lymphoplasmacytic interstitial nephritis with protein cast formation in the renal tubules. No neoplastic cell infiltrate was seen within the kidneys. In order to confirm plasma cell proliferation, immunohistochemistry (IHC) was performed on a Dako autoimmunostainer using the streptavidin-biotin complex method with the chromogen diamino-benzidine (DAB) (Dako, Glostrup, Denmark). The primary antibodies used were mouse anti-feline CD18 monoclonal antibody (produced by 
Dr. PF Moore, Clone:Fe3. 9F2), rabbit anti-human CD3 polyclonal antibody (Dako), rabbit anti-human CD20 polyclonal antibody (Biocare Medical, Concord, CA, U.S.A.), mouse anti-human CD79a monoclonal antibody (Biocare Medical, Clone:HM47/A9) and rabbit anti-human multiple myeloma oncogene 1 (MUM1) monoclonal antibody (Biocare Medical, Clone:BC5). Those antibodies were proven to be specific to the feline antigen. A previous report showed the specificity of anti-feline CD18 monoclonal antibody and anti-human CD3 polyclonal antibody [22]. The specificities of the remaining antibodies were tested by IHC with normal feline lymph node (data not shown). Almost all of the tumor cells were positive for CD18, CD79a (Fig. 4E) and MUM1 (Fig. 4F), but were negative for CD3 and CD20. Based on the morphological and immunohistochemical results, we concluded that the tumor cells originated from plasma cells.

In the current case, multiple neoplasms consisting of plasma cells had formed in not only the subcutaneous lesion but also in the liver and spleen. Bone marrow infiltration was not detected by aspiration cytology during the animal's lifetime, although post mortem examination of the bone marrow was not performed due to the owner's intention. Therefore, this case was diagnosed as subcutaneous extramedullary plasmacytoma with multiple abdominal organ infiltration. To the best of the authors' knowledge, this is the rare case of subcutaneous extramedullary plasmacytoma involving the abdominal organs without detectable bone lesions.

IHC for the diagnosis of feline MRDs shows the presence of immunoglobulin expression and the absence of CD3 [19]. CD79a is expressed by cells ranging from early B-cell progenitors to plasma cells and is detected in $32 \%$ of feline MRDs, according to a previous report [19]. MUM1 is expressed in the nuclei and cytoplasm of plasma cells and is strongly expressed in human MRDs [5]. A case report also exhibited MUM1 expression in feline MRD [11]. Therefore, plasma neoplastic cells can express both CD79a and MUM1. In line with this, IHC data, which were positive for CD79a and MUM1 (Fig. 4E and 4F), are consistent with feline MRD.

The survival duration of the current case was short. Morphologic categorization has been shown to correlate with prognosis in the cat, as well as in human myeloma $[3,19,27$, 31]. In previous studies, cats with well differentiated tumors have been shown to have increased median survival duration and frequency relative to those with poorly differentiated tumors. According to the results of a previous report, the present case was categorized as poorly differentiated MRD, because the proportion of plasmablasts was large and giant myeloma cells were present [19]. Therefore, this case had a poor prognosis, although this case was not treated with chemotherapeutic drugs other than prednisolone.

Hyperviscosity syndrome can result in cardiac insufficiency, retinal hemorrhage, renal failure, hemorrhagic diatheses and neurologic signs, which can decrease survival time in cats with multiple myeloma [6]. In the cat described here, protein cast formation in the kidneys assessed by post mortem histopathological examination and renal failure found in the hospital were consistent with the clinicohistopathological features of hyperviscosity syndrome. In addition, hyperglobulinemia was confirmed at that time. The degree of hyperviscosity is related to the severity of hyperglobulinemia and the immunoglobulin isotypes involved [25]. Hyperviscosity syndrome is associated with monoclonal gammopathy composed of $\operatorname{IgA}$, which is consistent with the larger size of these molecules as compared with the IgG isotype. Therefore, hyperviscosity syndrome associated with monoclonal IgA gammopathy is the most probable cause of death in the present case.

Immunoelectrophoresis and immunofixation of serum proteins can be used to confirm the diagnosis of plasma cell proliferation and the categorization of immunolabeling. There are no reports of these techniques being performed in feline MRDs, but reported in dogs with myeloma [10]. The immunoelectrophoresis data in the current case showed 2 discrete peaks in the gamma region. In addition, 2 immunoglobulin patterns were demonstrated by immunofixation. IgA was present in monomer and dimer states in the blood. For this reason, 2 peaks and bands were seen $[7,13]$. In addition, the light chains consistent with IgA lane were detected. Light chain expression in feline MRDs corresponds mainly to the lambda pattern. This is very similar to the physiologic distribution of light chains in normal plasma cells, which demonstrate primary expression of the lambda light chain [1]. On the other hand, monoclonal kappa light chain expression has been reported in 2 cats with MRDs [15, 19]. For accumulation of the clinical knowledge, we should have elucidated the light chain pattern in the cat.

Amyloid deposition was reported as one of the characteristic features in feline extramedullary plasmacytoma [17, 23, 26]. However, amyloid-like fibrillar materials were not detected in the tissue samples in this case, and these samples were negative for Congo red staining (data not shown). We presume that the pathological condition in the cat is different from that in the reported feline extramedullary plasmacytoma.

Interestingly, a previous report suggested that plasma cell tumor development might occur primarily in extramedullary locations in most cases of feline MRDs, in contrast to human MRD cases [19]. This supposition may affect therapeutic considerations. For example, human medicine routinely utilizes bisphosphonate therapy for MRDs [28] due to the rare occurrence of extramedullary plasmacytoma as compared to plasmacytoma with bone infiltration $[12,30]$. Therefore, we could not select an optimized therapy by referring to the general therapy of human MRDs.

In conclusion, this case describes a rare pattern of feline MRDs with extramedullary plasmacytoma involving the subcutaneous tissue, liver and spleen. To the authors' knowledge, this is the novel report of bimodal IgA gammopathy in feline MRDs detected by serum protein electrophoresis and immunofixation. This case showed aggressive biological behaviors with distant metastasis and hyperviscosity syndrome. In addition, the prognosis was considered worse than that of well differentiated feline MRDs. However, tumor infiltration of multiple locations is not definitely classified among the disease types of feline MRDs. Therefore, future studies are needed to accumulate case reports with similar clinicopathologic findings. 


\section{REFERENCES}

1. Arun, S. S., Breuer, W. and Hermanns, W. 1996. Immunohistochemical examination of light-chain expression (lambda/kappa ratio) in canine, feline, equine, bovine and porcine plasma cells. Zentralbl. Veterinarmed. A 43: 573-576. [Medline] [CrossRef]

2. Carpenter, J. L., Andrews, L. K. and Holzworth, J. 1987. Tumours and tumour like lesions. pp. 406-596. In: Disease of the Cat: Medicine and Surgery, 1st ed. (Holzworth, J. ed.), WB Saunders, Philadelphia.

3. Carter, A., Hocherman, I., Linn, S., Cohen, Y. and Tatarsky, I. 1987. Prognostic significance of plasma cell morphology in multiple myeloma. Cancer 60: 1060-1065. [Medline] [CrossRef]

4. Engle, G. C. and Brody, R. S. 1969. A retrospective study of 395 feline neoplasms. J. Am. Anim. Hosp. Assoc. 5: 21-31.

5. Falini, B., Fizzotti, M., Pucciarini, A., Bigerna, B., Marafioti, T., Gambacorta, M., Pacini, R., Alunni, C., Natali-Tanci, L., Ugolini, B., Sebastiani, C., Cattoretti, G., Pileri, S., Dalla-Favera, R. and Stein, H. 2000. A monoclonal antibody (MUM1p) detects expression of the MUM1/IRF4 protein in a subset of germinal center B cells, plasma cells, and activated T cells. Blood 95: 2084-2092. [Medline]

6. Forrester, S. D., Greco, D. S. and Relford, R. L. 1992. Serum hyperviscosity syndrome associated with multiple myeloma in two cats. J. Am. Vet. Med. Assoc. 200: 79-82. [Medline]

7. Gavrilova, E. M., Egorov, A. M. and Shakhanina, K. L. 1976. [Isolation and immunochemical study of monomer and dimer forms of IgA human globulins]. Biokhimiia 41: 684-691. [Medline]

8. Hickford, F. H., Stokol, T., vanGessel, Y. A., Randolph, J. F. and Schermerhorn, T. 2000. Monoclonal immunoglobulin G cryoglobulinemia and multiple myeloma in a domestic shorthair cat. J. Am. Vet. Med. Assoc. 217: 1029-1033, 1007-1008. [Medline] [CrossRef]

9. Holzworth, J. and Meier, H. 1957. Reticulum cell myeloma in a cat. Cornell Vet. 47: 302-316. [Medline]

10. Jacobs, R. M. 1982. The qualitative analysis of canine immunoglobulins and myeloma proteins by immunofixation. Vet. Clin. Pathol. 11: 7-10. [Medline] [CrossRef]

11. Kagawa, Y., Yamashita, T., Maetani, S., Aoki, Y., Sakaguchi, K., Hirayama, K., Umemura, T. and Taniyama, H. 2011. Cutaneous lymphoplasmacytic lymphoma with systemic metastasis in a cat. J. Vet. Med. Sci. 73: 1221-1224. [Medline] [CrossRef]

12. Kapadia, S. B. 1980. Multiple myeloma: a clinicopathologic study of 62 consecutively autopsied cases. Medicine (Baltimore) 59: 380-392. [Medline] [CrossRef]

13. Kato, H., Momoi, Y., Omori, K., Youn, H. Y., Yamada, T., Goto, N., Ono, K., Watari, T., Tsujimoto, H. and Hasegawa, A. 1995. Gammopathy with two M-components in a dog with IgA-type multiple myeloma. Vet. Immunol. Immunopathol. 49: 161-168. [Medline] [CrossRef]

14. King, A. J., Davies, D. R. and Irwin, P. J. 2002. Feline multiple myeloma: literature review and four case reports. Aust. Vet. Pract. 32: 146-151.

15. Kyriazidou, A., Brown, P. J. and Lucke, V. M. 1989. Immunohistochemical staining of neoplastic and inflammatory plasma cell lesions in feline tissues. J. Comp. Pathol. 100: 337-341. [Medline] [CrossRef]

16. Longo, D. L. 1998. Plasma cell disorders. pp. 712-718. In: Harrison's Principles of Internal Medicine, 14th ed. (Fauci, A. S. ed.), McGraw-Hill, New YorK.

17. Majzoub, M., Breuer, W., Platz, S. J., Linke, R. P., Linke, W. and Hermanns, W. 2003. Histopathologic and immunophenotypic characterization of extramedullary plasmacytomas in nine cats. Vet. Pathol. 40: 249-253. [Medline] [CrossRef]

18. Mellor, P. J., Haugland, S., Murphy, S., Smith, K. C., Holloway,
A., Archer, J., Powell, R. M., Polton, G. A., Tasker, S., McCormick, D., Tempest, M. E., McNeil, P. E., Scase, T. J., Knott, C. D., Bonfanti, U., Villiers, E. J., Argyle, D. J., Herrtage, M. E. and Day, M. J. 2006. Myeloma-related disorders in cats commonly present as extramedullary neoplasms in contrast to myeloma in human patients: 24 cases with clinical follow-up. J. Vet. Intern. Med. 20: 1376-1383. [Medline] [CrossRef]

19. Mellor, P. J., Haugland, S., Smith, K. C., Powell, R. M., Archer, J., Scase, T. J., Villiers, E. J., McNeil, P. E., Nixon, C., Knott, C., Fournier, D., Murphy, S., Polton, G. A., Belford, C., Philbey, A. W., Argyle, D. J., Herrtage, M. E. and Day, M. J. 2008. Histopathologic, immunohistochemical, and cytologic analysis of feline myeloma-related disorders: further evidence for primary extramedullary development in the cat. Vet. Pathol. 45: 159-173. [Medline] [CrossRef]

20. Mochizuki, H., Takahashi, M., Nishigaki, K., Ide, T., GotoKoshino, Y., Watanabe, S., Sato, H., Sato, M., Kotera, Y., Fujino, Y., Ohno, K., Uchida, K. and Tsujimoto, H. 2011. Establishment of a novel feline leukemia virus (FeLV)-negative B-cell cell line from a cat with B-cell lymphoma. Vet. Immunol. Immunopathol. 140: 307-311. [Medline] [CrossRef]

21. Omori, M., Pu, R., Tanabe, T., Hou, W., Coleman, J. K., Arai, M. and Yamamoto, J. K. 2004. Cellular immune responses to feline immunodeficiency virus (FIV) induced by dual-subtype FIV vaccine. Vaccine 23: 386-398. [Medline] [CrossRef]

22. Pinto da Cunha, N., Ghisleni, G., Scarampella, F., Fabbrini, F., Sforna, M., Cornegliani, L., Caniatti, M., Avallone, G., Moore, P. and Roccabianca, P. 2014. Cytologic and immunocytochemical characterization of feline progressive histiocytosis. Vet. Clin. Pathol. 43: 428-436. [Medline] [CrossRef]

23. Platz, S. J., Breuer, W., Geisel, O., Linke, R. P. and Hermanns, W. 1997. Identification of lambda light chain amyloid in eight canine and two feline extramedullary plasmacytomas. J. Comp. Pathol. 116: 45-54. [Medline] [CrossRef]

24. Radhakrishnan, A., Risbon, R. E., Patel, R. T., Ruiz, B. and Clifford, C. A. 2004. Progression of a solitary, malignant cutaneous plasma-cell tumour to multiple myeloma in a cat. Vet. Comp. Oncol. 2: 36-42. [Medline] [CrossRef]

25. Ramaiah, S. K., Seguin, M. A., Carwile, H. F. and Raskin, R. E. 2002. Biclonal gammopathy associated with immunoglobulin A in a dog with multiple myeloma. Vet. Clin. Pathol. 31: 83-89. [Medline] [CrossRef]

26. Rowland, P. H. and Linke, R. P. 1994. Immunohistochemical characterization of lambda light-chain-derived amyloid in one feline and five canine plasma cell tumors. Vet. Pathol. 31: 390-393. [Medline] [CrossRef]

27. Sukpanichnant, S., Cousar, J. B., Leelasiri, A., Graber, S. E., Greer, J. P. and Collins, R. D. 1994. Diagnostic criteria and histologic grading in multiple myeloma: histologic and immunohistologic analysis of 176 cases with clinical correlation. Hum. Pathol. 25: 308-318. [Medline] [CrossRef]

28. Terpos, E., Dimopoulos, M. A. and Sezer, O. 2007. The effect of novel anti-myeloma agents on bone metabolism of patients with multiple myeloma. Leukemia 21: 1875-1884. [Medline] [CrossRef]

29. Vail, D. M. 2007. Plasma cell neoplasms. pp. 768-784. In: Small Animal Clinical Oncology, 4th ed. (Withrow, S. J. and Vail, D. M. eds.), W.B. Saunders, Philadelphia.

30. Woodruff, R. K., Whittle, J. M. and Malpas, J. S. 1979. Solitary plasmacytoma. I: Extramedullary soft tissue plasmacytoma. Cancer 43: 2340-2343. [Medline] [CrossRef]

31. Wutke, K., Várbíró, M., Rüdiger, K. D. and Kelényi, G. 1981. Cytological and histological classification of multiple myeloma. Haematologia (Budap.) 14: 315-329. [Medline] 